\title{
Biopsychosocial Factors Affecting the Risk of Musculoskeletal Disorders in Surakarta, Central Java
}

\author{
Dea Linia Romadhoni'), Setyo Sri Rahardjo²), Dono Indarto²) \\ 1)Masters Program in Public Health, Universitas Sebelas Maret \\ ${ }^{2)}$ Department of Public Health, Faculty of Medicine, Universitas Sebelas Maret
}

\begin{abstract}
Background: Musculoskeletal Disorders (MSDs) are injuries and disorders that affect the human body's movement or musculoskeletal system (i.e. muscles, tendons, ligaments, nerves, discs, blood vessels, etc.). The impacts of MSD include reduced activity, reduction of work ability, and use of health care (seeing a health professional or taking prescription or nonprescription medication). Studies investigating risk factors of MSD are lacking in Indonesia. The purpose of this study was to investigate biopsychosocial factors affecting the risk of MSD in Surakarta, Central Java.

Subjects and Method: This was an analytic observational study with a cross-sectional design. The study was carried out at Dr. Moewardi hospital, Surakarta, Central Java from April to May 2018. A sample of 116 patients was selected by fixed disease sampling. The dependent variable was MSD. The independent variable were gender, history of chronic disease, body mass index (BMI), stress, occupational type, environmental working, and working posture. Data on MSD status were taken from medical record. Working posture was measured by REBA questionnaire. Other data were collected by questionnaire. The data were analyzed by path analysis.

Results: The risk of MSDs was directly increased with $\mathrm{BMI} \geq 25(\mathrm{OR}=1.22 ; 95 \% \mathrm{CI}=0.15$ to 2.30 ; $\mathrm{p}=0.026)$, history of chronic disease $(\mathrm{OR}=2.02 ; 95 \% \mathrm{CI}=0.96$ to $3.08 ; \mathrm{p}<0.001)$, heavy occupational type $(\mathrm{OR}=1.56 ; 95 \% \mathrm{CI}=0.43$ to $2.68 ; \mathrm{p}<0.007)$, and poor working posture (REBA score $\geq 4)(\mathrm{OR}=1.75 ; 95 \% \mathrm{CI}=0.65$ to $-2.86 ; \mathrm{p}=0.002)$. The risk of MSDs was indirectly affected by environmental working, stress, and gender.

Conclusion: The risk of MSDs is directly increased with BMI $\geq 25$, history of chronic disease, heavy occupational type, and poor working posture (REBA score $\geq 4$ ), and is indirectly affected by environmental working, stress, and gender.
\end{abstract}

Keywords: musculoskeletal disorders, biopsychosocial factor

\section{Correspondence:}

Dea Linia Romadhoni. Masters Program in Public Health, Universitas Sebelas Maret, Jl. Ir. Sutami No. 36 A, Surakarta, Indonesia. Email: dealiniao8@gmail.com.

Mobile: +6282227862718 .

\begin{abstract}
BACKGROUND
Musculoskeletal disorders (MSDs) are the biggest cause of work absenteeism in the United States. The most common musculoskeletal injuries are sprains and strains. Similar problems also occur in Brazilian workers, the most commonly affected part of the body is the shoulder (49\%), followed by the neck (47\%) and the back (39\%) (Kim, 2017). In Indonesia, there are 62.5\% complaining of low musculoskeletal disor-
\end{abstract}

ders and $37.5 \%$ with high musculoskeletal disorders in computer workers (Tofan et al., 2017).

According to WHO (2009), the risk factors contributing to cases of MSDs are social factors, whereas according to Costa and Vieira (2010) the risk factors that resulted in MSDs include social factors, biomechanical factors as well as biological factors. According to another study intrinsic social factors also influence the risk of musculoskeletal disorders (Bevan, 2015). 
Journal of Epidemiology and Public Health (2018), 3(3): 361-368

https://doi.org/10.26911/jepublichealth.2018.03.03.07

Biological, psychological, and social factors are important to learn to know the influence of forces from within and from outside. The biological factor in question is gender i.e. women tend to be at higher risk of MSDs compared to men who $<10 \%$ only have MSDs compared with women (Messing et al., 2015), body mass index is associated with every $3.8 \mathrm{~kg}$ increase/ $\mathrm{m}^{2}$ may increase by $40 \%$ risk of MSDs (Alahmari et al., 2017), a person's age $>35$ years will be at higher risk of MSDs (Costa and Vieira, 2010).

The psychosocial factors include the heavier the work of a person then $72.7 \%$ high levels of stress so that more at risk of MSDs (Ahlgren et al., 2012), the type of work of a person affects how high the risk of MSDs are exposed to workers with excess physical activity $76.2 \%$ are at risk for MSDs (Yi and Chan., 2016), an ergonomic work environment will increase the risk of MSDs by $20 \%$ and other studies suggest a poor work environment increases $34.4 \%$ (Tofan et al., 2017), and not ergonomic with the body position settled in a few hours can increase the MSDs by $62.8 \%$ (Chinyere, 2014).

Based on the description above, many workers can become outpatients in a hospital with complaints of musculoskeletal disorders accompanied by other supporting factors such as biological, psychological and social considerations that may affect the risk of musculoskeletal disorders. The biological factors include Body Mass Index (BMI), history of disease, and also sex. Psychosocial factors are stress level, occupation type, work environment and work posture.

\footnotetext{
SUBJECTS AND METHOD

1. Study Design

This is an observational analytic study with cross-sectional approach. This cross-sec-
}

tional study was performed on out-patient MSDs.

\section{Population and Samples}

The target population in this study was outpatient MSDs patients in Poly Physiotherapy Dr. Moewardi hospital, Surakarta. A sample of 116 patients was selected by fixed disease sampling.

The inclusion criteria are patients with status as workers/ employees, working $\geq 8$ hours, willing to be respondent and aged 30-60 years. The exclusion criteria for patients who have a history of fracture, have spinal abnormalities, and have a history of smoking.

\section{Study Variables}

The dependent variable was MSDs. The independent variables were body mass index (BMI), history of disease, gender, stress, and work environment, occupational type, and work posture.

\section{Operational Definition of Variables}

BMI was defined as an indicator of patient nutritional status related to deficiency or excess body weight. Data on weight was measured by weight scale. Data on height was measured by microtoise. The measurement scale was continuous, but for the purpose of data analysis, it was transformed into dichotomous, coded o for normal weight $(<25)$ and 1 for overweight (BMI $\geq 25$ ).

A history of disease was defined as presence or absence of disease that may cause or be associated with MSDs, such as diabetes mellitus, tuberculosis, or hypertension. The data were collected by medical record. The measurement scale was categorical, coded o for no and 1 for yes.

Sex was defined as a biological feature that is determined biologically and anatomically from birth and is expressed in the type of male or female. The data were collected by questionnaire. 
Type of occupation was defined as a form of activities undertaken by patients to earn income. The data were collected by questionnaire. The measurement scale was continuous.

Work environment was defined as all that is located around the workplace that can affect the research subject either directly or indirectly, and the form of activities undertaken by the subject obtained using Plan for Identifiering Belastning factor (PLIBEL) checklist.

Working posture was defined as the state of the body, body shape, and posture of a person when doing a job. The data were measured by rapid entire body assessment (REBA) questionnaire.

Stress level was defined as the auto body's response reaction to psychosocial stressor or mental stress in life. The data were collected by questionnaire. The measurement scale was continuous.

MSDs were defined as complaints on the skeletal muscle sections felt by a person ranging from very mild to very painful complaints usually characterized by one or more symptoms of pain, heat, numbness, swellling, stiffness and stiffness on one or more parts of the body of the data taken on the basis of medical records of doctor's diagnosis.

\section{Instruments}

BMI, history of disease, sex, occupation type, stress level, work environment were collected using questionnaires and working posture was obtained using REBA index.

\section{Data Analysis}

The univariate analysis was conducted to see the frequency distribution and percentage characteristics of subjects. The bivariate analysis was conducted to study the relationship between MSDs and the independent variable using chi-square test and odds ratio calculation (OR) with confidence level (CI) of 95\%. The multivariate analysis was done using path analysis.

\section{Research Ethics}

The research ethics include informed consent, anonymity, confidentiality and ethical clearance. The ethical clearance in this study was conducted in Dr. Moewardi hospital, Surakarta.

\section{RESULTS}

\section{Subjects of Characteristics}

Table 1 shows the characteristics of the study subject. Table 1 showed that study subjects with MSDs were $57.8 \%$. As many as $56.9 \%$ study subjects had light occupational type. As many as $64.7 \%$ of the study subjects had BMI <25.

\section{Path Analysis}

Path analysis run on Stata 13, including 7 observed variables, 3 endogenous variables, and 5 exogenous variables 5 , so the degree of freedom (df) is 10 (over identified). It means that path analysis can be done. Path analysis model was depicted in Figure 1. The result of path analysis was described in Table 2.

Table 2 showes that BMI was directly and positively associated with MSDs and it was statistically significant. BMI $\geq \mathbf{2 5}$ increased the risk of MSDs $(b=1.22 ; 95 \%$ $\mathrm{CI}=0.15$ to $2.30 ; \mathrm{p}=0.026$ ).

History of illness was directly and positively associated with MSDs and it was statistically significant. History of illness increased the risk of MSDs $(b=2.02 ; 95 \%$ $\mathrm{CI}=0.96$ to 3.08 ; $\mathrm{p}<0.001$ ).

Occupational type was directly and positively associated with MSDs and it was statistically significant. Heavy occupational type increased the risk of MSDs $(b=1.56$; 95\% $\mathrm{CI}=0.43$ to 2.68 ; $\mathrm{p}<0.007$ ).

Working posture was directly and positively associated with MSDs and it was statistically significant. Poor working posture (REBA scores $\geq 4$ ) increased the 
Journal of Epidemiology and Public Health (2018), 3(3): 361-368

https://doi.org/10.26911/jepublichealth.2018.03.03.07

risk of MSDs $(b=1.75 ; 95 \% \mathrm{CI}=-0.65$ to 2.86; $\mathrm{p}=0.002$ ).

MSDs was indirectly affected by sex, stress, and work environment. Type of work was affected by male sex $(b=-0.90 ; 95 \%$ $\mathrm{CI}=-1.65$ to $-1.15 ; \mathrm{p}=0.019$ ).
Poor working posture was affected by stress $(\mathrm{b}=0.79 ; 95 \% \mathrm{CI}=0.01$ to $1.58 ; \mathrm{p}=$ 0.047) and poor work environment $(\mathrm{b}=$ 1.07 ; $95 \% \mathrm{CI}=0.28$ to $1.85 ; \mathrm{p}=0.008$ ).

Table 1. Study Subject Characteristics

\begin{tabular}{llcc}
\hline \multicolumn{1}{c}{ Characteristics of Subjects } & \multicolumn{1}{c}{ Criteria } & Frequency & (\%) \\
\hline Sex & Male & 52 & 44.8 \\
\multirow{2}{*}{ History of diseases } & Female & 64 & 55.2 \\
& No & 58 & 50 \\
BMI & Yes & 58 & 50 \\
\multirow{2}{*}{ Stress Level } & $<25$ & 75 & 64.7 \\
\multirow{2}{*}{ Type of Work } & $\geq 25$ & 41 & 35.3 \\
\multirow{2}{*}{ Working Environment } & $<26$ & 54 & 47.4 \\
\multirow{2}{*}{ Working Posture } & $\geq 26$ & 61 & 52.6 \\
\multirow{2}{*}{ MSDs } & Light & 66 & 56.9 \\
& Heavy & 50 & 43.1 \\
& $<43 \%$ & 56 & 48.3 \\
& $>43 \%$ & 60 & 51.7 \\
& $\leq 4$ & 53 & 45.7 \\
& $\geq 4$ & 63 & 54.3 \\
& Acute & 67 & 57.8 \\
\hline
\end{tabular}

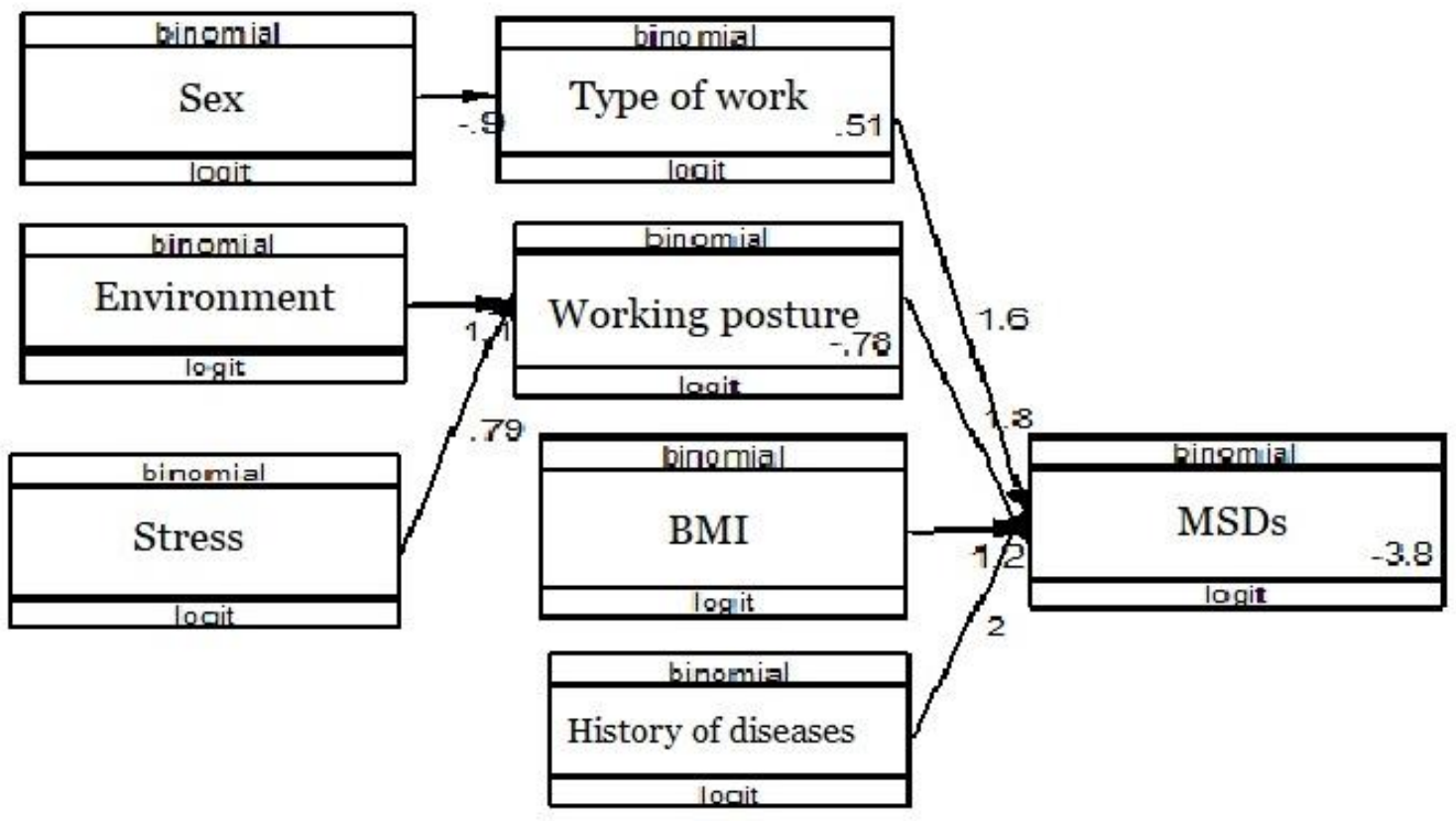

Figure 1. Structural model with estimate 
Table 2. The results of path analysis of biological, psychological, and social factor effects on musculoskeletal disorders (MSDs)

\begin{tabular}{|c|c|c|c|c|c|}
\hline \multirow[b]{2}{*}{ Dependent variable } & \multirow[b]{2}{*}{ Independent Variable } & \multirow[b]{2}{*}{$\mathbf{b}$} & \multicolumn{2}{|c|}{ 95\% CI } & \multirow[t]{2}{*}{$\mathbf{p}$} \\
\hline & & & $\begin{array}{c}\text { Lower } \\
\text { limit }\end{array}$ & $\begin{array}{c}\text { Upper } \\
\text { limit }\end{array}$ & \\
\hline \multicolumn{6}{|l|}{ Direct Effects } \\
\hline MSDs & $\leftarrow \quad \mathrm{BMI} \geq 25$ & 1.22 & 0.15 & 2.30 & 0.026 \\
\hline MSDs & $\leftarrow \quad$ History of diseases & 2.02 & 0.96 & 3.08 & $<0.001$ \\
\hline MSDs & $\leftarrow \quad$ Heavy occupation & 1.56 & 0.43 & 2.68 & 0.007 \\
\hline MSDs & $\leftarrow \quad$ Poor working posture & 1.75 & 0.65 & 2.86 & 0.002 \\
\hline \multicolumn{6}{|l|}{ Indirect Effects } \\
\hline Poor working posture & $\leftarrow \quad$ Poor working posture & 1.07 & 0.28 & 1.85 & 0.008 \\
\hline Poor working posture & $\leftarrow$ Stress & 0.79 & 0.01 & 1.58 & 0.047 \\
\hline Heavy occupation & $\leftarrow \quad$ Male sex & -0.90 & -1.65 & -1.15 & 0.019 \\
\hline Log likelihood & -198.99 & & & & \\
\hline AIC & 413.98 & & & & \\
\hline BIC & 445.51 & & & & \\
\hline
\end{tabular}

\section{DISCUSSIONS \\ 1. The effect of BMI on the risk of MSDs}

This study showed that there was a direct effect between BMI and the risk of MSDs which was statistically significant. The results of the analysis in this study showed that workers with exceeded BMI and obesity would increase the risk of MSDs.

BMI assessment was performed by using a weight scale with kilogram $(\mathrm{Kg})$ and anthropometry of height in centimeters (cm) then calculated by using BMI formula and the result was obtained by classifying it into 3 categories according to WHO (Viester et al., 2013).

Overweight was also found to increase the development of osteoarthritis (OA) as well as rheumatoid arthritis (RA) because in every enhancement of BMI by $3.8 \mathrm{~kg} /$ $\mathrm{m} 2$, the risk of arthritis development was increased by $40 \%$. The disorder was caused by an enhancement in inflammation that affected the Range of Motion (ROM) in people with MSDs, this was also caused by the enhancement of thigh circumference that can stimulate the genu varum, thus increasing the strength of pressure on the knee, in conclusion, the enhancement of thigh volume was equal to varus en- hancement on the knee (Alahmari et al., 2017).

\section{The effect of history of illness on the risk of MSDs}

This study showed that there was a direct effect between history of illness and the risk of MSDs which was statistically significant. The results of the analysis in this study showed that workers who have history of illness increased the risk of MSDs than workers who did not have history of illness. A history of illness was related to musculoskeletal disorders cases such as heart disease, diabetes, and depression, this might increase the risk of MSDs but it can be prevented by doing physical activity (McPhail et al, 2014).

According to Kelly et al (2009), there were several causes of musculoskeletal disorders that occur in the case of Frozen Shoulder including systemic factors caused by diabetes mellitus, hypertension, and other metabolic conditions, and also extrinsic factors caused by cardiopulmonary, cervical, CVA, humeral fractures, and Parkinson.

\section{The effect of occupational type on the risk of MSDs}

This study showed that there was a direct effect between occupational type and the 
Journal of Epidemiology and Public Health (2018), 3(3): 361-368

https://doi.org/10.26911/jepublichealth.2018.03.03.07

risk of MSDs which was statistically significant. The results of the analysis in this study showed that workers with heavy occupational types would increase the risk of MSDs rather than workers with moderate and easy types of work. In general, almost all types of job have a risk of MSDs, for example, construction workers who were required to perform repetitive movements with high strength and body movements that increased the risk of MSDs (Yi and Chan, 2016).

Restaurant workers would bring many items by using one hand, this was obviously very uncomfortable to do so that the burden was placed only on one side of the body, therefore, the risk of MSDs was increased (Laperrière et al, 2017).

\section{The effect of working posture on the risk of MSDs}

This study showed that there was a direct effect between working posture and the risk of MSDs which was statistically significant. The results of the analysis in this study showed that workers with poor work postures would increase the risk of MSDs than workers with good work postures. Working posture was the position of the body at work, working postures were divided into three kinds, namely easy posture, fatigue posture, and stiff posture (Rahman, 2014).

Working posture can contributed to musculoskeletal disorders, for example, a bad seat can worsen the working posture which lead to the tension in lower back, and the seat which was too high can cause loss of circulation on the foot (Chinyere, 2014). Work posture measurements can be done by using Replicate Body Assessment (REBA), which would be obtained in the form of 5 categories of REBA scores, namely very low, low, medium, high and very high of MSDs risk levels (Rafeemanesh et al, 2013).

\section{The effect of work environment on the Risk of MSDs Through working posture}

This study showed that there was an indirect effect between work environment and the risk of MSDs through working posture. The results of this study showed that poor work environment affected poor working postures and increased the risk of MSDs. The work environment was everything in the workplace or the circumstances around the workplace such as the ventilation system, the dust in the office, room temperature, humidity, the lighting in the office (lighting intensity), noise levels in the work area, and workplace design (Sharma and Singh, 2015).

A poor work environment can be identified by using the Plan for Identifiering av Belastning factor (PLIBEL) method, PLIBEL was designed to assess the ergonomic risk in the five body regions: neck shoulders, upper back, elbows, forearm, hand, knees, hips, and low back. The advantage of this method was it can be used as a screening tool in occupational health and safety (Reid and McCauleyBush, 2009).

\section{The effect of stress level on the risk of MSDs through working posture}

This study showed that there was an indirect effect between stress level and the risk of MSDs through working posture which was statistically significant. The results of the analysis in this study showed that workers with high stress level would affect poor working posture which increased the risk of MSDs. The level of stress was an auto body response to psychosocial stressor or mental stress in the life burden with many causal factors (Hartono, 2011).

High stress level would lead to MSDs, this was due to an enhancement in muscle tension caused by stress hormones (Bergsten et al, 2015). The stress level can 
be measured by using Precived Stress Scale (PSS) and questions based on questionnaire which consisted of 10 items and 4 answer columns containing 0-4 scores, then the total answers were accumulated with stress level categories based on PSS ranging from mild stress, medium stress, and severe stress (Khalili et al., 2017).

\section{The effect of gender on the risk of MSDs through occupational type}

This study showed that there was an indirect effect between gender and the risk of MSDs through occupational type which was statistically significant. The results of the analysis in this study showed that female workers were less likely to have MSDs related to their occupations compared to male workers. Men and women were differentiated based on their posture. In doing a job, they were required to perform their jobs with the same workload and working posture, this situation could caused women to have MSDs (Ahlgren et al, 2012).

One case has been found that men were two times more likely to be exposed to musculoskeletal disorders on lower extermity while women were nine times more likely to have the risk, this might be due to the requirements of a job in which they were required to wear high heels that feel uncomfortable and run faster than usual, therefore, women used their maximum physical capacity (Laperrière et al, 2017).

\begin{tabular}{l}
\hline REFERENCES \\
\hline Ahlgren C, Malmgren OEB, Brulin C \\
(2012). Gender analysis of musculo- \\
skeletal disorders and emotional \\
exhaustion: interactive effects from \\
physical and psychosocial work expo- \\
sures and engagement in domestic \\
work. Ergonomics, 55(2), 212-228. \\
https://doi.org/10.1080/o0140139.- \\
2011.646319.
\end{tabular}

Alahmari KA, Silvian PS, Reddy RS, Ahmad I, Kakaraparthi VN, Alam MM (2017). Mediating role of body mass index in knee osteoarthritis. Journal of Taibah University Medical Sciences, 12(2), 150-156. https://doi.org/10.1016/j.jtumed.2016.11.010.

Bevan S (2015). Economic impact of musculoskeletal disorders (MSDs) on work in Europe. Best Practice and Research: Clinical Rheumatology, 29(3), 356-373.

Chinyere NI (2014). Influence of Workstation and Work Posture Ergonomics on Job Satisfaction of Librarians in the Federal and State University Libraries in Southern Nigeria. IOSR Journal of Humanities and Social Science, 19(9), 78-84.

Costa BR, Vieira ER (2010). Risk factors for work-related musculoskeletal disorders: A systematic review of recent longitudinal studies. American Journal of Industrial Medicine, 53(3), $285-323$.

Hartono (2011). Stres \& Stroke. Cetakan kelima. Yogyakarta : Kanisius

Khalili R, Sirati NM, Ebadi A, Tavallai A, Habibi M (2017). Validity and reliability of the Cohen 10-item Perceived Stress Scale in patients with chronic headache: Persian version. Asian Journal of Psychiatry, 26, 136-140.

Kelley MJ, Mcclure PW, Leggin BG (2009). Frozen Shoulder: Evidence and a Proposed Model Guiding Rehabilitation. Journal of Orthopaedic \& Sports Physical Therapy, 39(2), 135-148. https://doi.org/10.2519/jospt.2009.2916.

Kim IJ (2017). The Role of Ergonomics for Construction Industry Safety and Health Improvements. Journal of Ergonomics, 7(2): 2-5.

Laperriere E, Messing K, Bourbonnais R (2017). Work activity in food service: 
Journal of Epidemiology and Public Health (2018), 3(3): 361-368

https://doi.org/10.26911/jepublichealth.2018.03.03.07

The significance of customer relations, tipping practices and gender for preventing musculoskeletal disorders. Applied Ergonomics, 58, 89-101.

McPhail SM, Schippers M, Marshall AL (2014). Age, physical inactivity, obesity, health conditions, and healthrelated quality of life among patients receiving conservative management for musculoskeletal disorders. Clinical Interventions in Aging, 9, 1069-1080. Messing K, Stock S, Cote J, Tissot F (2015). Is sitting worse than static standing? how a gender analysis can move us toward understanding determinants and effects of occupational standing and walking. Journal of Occupational and Environmental Hygiene, 12(3), D11-D17.

Tofan AEP, Eka, Rosanti, Ratih AR (2017). Analysis of Factors Causing Musculoskeletal Disorders using Rula (Rapid Upper Limb Assessment) Method in Computer Operators. International Journal of Applied Environmental Sciences. 12(2), 323-340.

Rafeemanesh E, Jafari Z, Kashani FO, Rahimpour F (2013). A study on job postures and musculoskeletal illnesses in dentists. International Journal of Occupational Medicine and Environmental Health, 26(4), 615-620. https://doi.org/10.2478/s13382-0130133-z.
Rahman CML (2014). Study and Analysis of Work Postures of Workers Working in A Ceramic Industry Through Rapid Upper Limb Assessment (RULA). International Journal of Engineering and Applied Sciences.5(3).

Sharma R, Singh R (2015). Work-Related Musculoskeletal Disorders, Job Stressors and Gender Responses in Foundry Industry Work-Related Musculoskeletal Disorders, Job Stressors and Gender Responses in Foundry Industry. International Journal of Occupational Safety and Ergonomics, 3548.

Reid CRD, McCauley BP (2009). Occupational Lower Extremity Risk Assessment Modeling. Department of Industrial Engineering \& Management Systems: Spring Term.

Viester L, Verhagen EA, Hengel KMO, Koppes LL, Van DBAJ, Bongers PM (2013). The relation between body mass index and musculoskeletal symptoms in the working population. BMC Musculoskeletal Disorders, 14(1), 238. https://doi.org/10.1186/1471-2474-14238.

Yi W, Chan A (2016). Health profile of construction workers in Hong Kong. International Journal of Environmental Research and Public Health, 13(12). https://doi.org/10.339o/ijerph13121232. 